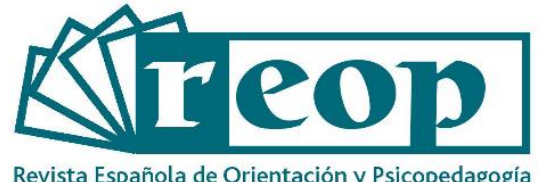

\title{
Athanasou, J. A., y Perera, H. N. (eds.). (2019). International Handbook of Career Guidance (2⿺ ed.). Springer, 851 páginas. ISBN: 978-3-030-25153-6
}

\begin{abstract}
Este manual, que coordinan Athanasou y Perera en su segunda edición de 2019, presenta el recorrido de la orientación profesional desde sus inicios incluyendo su aplicación práctica. Se trata de una obra que pretende ser un referente tanto para investigadores y académicos, como para aquellos profesionales que desarrollan su actividad dentro del área de la orientación profesional y el desarrollo de la carrera.
\end{abstract}

En esta segunda edición, que se complementa con la primera, los editores de la obra han contado con la participación internacional de 38 colaboradores, de gran prestigio en el mundo de la orientación profesional, como Savickas, McMahon y Patton, entre otros. Esta colaboración ofrece al lector no un único y defendido punto de vista, si no que se aporta una visión holística y complementaria de la orientación profesional.

La obra, que se estructura en 39 capítulos, comienza con un capítulo introductorio donde se habla de la esencia de la orientación y se presenta la obra. Los siguientes 38 capítulos se encuentran organizados en cuatro grandes partes que se describen a continuación.

La primera parte, destinada a abordar los "Fundamentos teóricos" de la orientación profesional, comprende los capítulos del 2 al 9 con un componente eminentemente teórico. Se centran en fundamentar de manera teórica la orientación profesional incluyendo la evolución en sus referentes y enfoques teóricos. Específicamente, en esta primera parte se aglutinan capítulos sobre la historia de la orientación profesional, las principales teorías de la carrera que han influido en su desarrollo, las influencias del constructivismo social, la teoría de sistemas, la visión cognitiva social o la psicología del trabajo, así como los diferentes modelos adoptados para llevarla a la práctica, modelos de toma de decisiones y orientación profesional.

La segunda parte de la obra lleva por título "Orientación profesional en la práctica", y se corresponde con los capítulos del 10 al 21. En ella se aborda el desarrollo de la orientación profesional haciendo hincapié en su aplicación práctica, teniendo en cuenta todas las etapas de desarrollo a lo largo de la vida de la persona y los contextos cambiantes. Se parte desde la infancia llegando la jubilación y, también se trata su desarrollo cuando se trabaja con colectivos diversos, como las personas con discapacidad, la sobredotación, las personas refugiadas, las mujeres, etc.

Los capítulos del 22 al 26 pertenecen a la tercera parte denominada "Orientación educativa y vocacional en un contexto social". En esta parte se habla del papel que juega el contexto social en el desarrollo de la persona entendida como un "sistema vivo". Se pone de manifiesto la importancia de la consideración de ambos aspectos tanto en la teoría como en la práctica orientadora en el contexto profesional. 
Para finalizar, la última parte referida a las "Pruebas, valoración y evaluación en educación y orientación profesional, se desarrolla de los capítulos del 27 al 39. En estos capítulos el/la lector/a se encuentra con las implicaciones sobre las prácticas en orientación profesional y educación, de las evaluaciones llevadas a cabo teniendo en cuenta intereses, diferentes contextos, y recursos, utilizando la Red de Información Ocupacional ( $\mathrm{O}^{\star} \mathrm{NET}$ ) y haciendo alusión al abuso que, en ocasiones, se realiza de las pruebas psicométricas en la evaluación psicopedagógica. También se destaca la importancia de los aspectos éticos en la práctica de la orientación para el desarrollo de la carrera.

Se presenta por lo tanto en esta obra, un recorrido amplio, en profundidad y, desde diferentes perspectivas, del nacimiento, desarrollo, y aplicación de la orientación profesional. Un desarrollo y una práctica que no permanece ajena a las influencias de las diferentes teorías que la conforman, a las características de los contextos en los que se desarrolla y, a la diversidad de características y demandas de sus usuarios/as a lo largo de toda su vida. Una orientación profesional en la que hay que seguir trabajando para lograr dar respuesta a las crecientes y nuevas demandas de la sociedad y sus ciudadanos/as, en un contexto social complejo y cambiante. En resumen, estamos ante un manual teórico-práctico, elaborado por un elenco amplio de profesionales de gran relevancia mundial, que no debería faltar en la biblioteca de ningún investigador/a, educador/a o profesional de la orientación profesional que se dedique a la orientación de personas.

Marisa Fariña-Sánchez

Doctoranda, Facultad de Ciencias de la Educación Universidad de Sevilla

\section{Cómo citar esta recensión:}

Fariña-Sánchez, M. (2021). Athanasou, J. A., y Perera, H. N. (eds.). (2019). International Handbook of Career Guidance (2 $2^{\mathrm{a}}$ ed.). Springer, 851 páginas. ISBN: 978-3-030-25153-6. [Reseña] Revista Española de Orientación y Psicopedagogía, 32(3), 155-156. https://doi.org/10.5944/reop.vol.32.num.3.2021.32562 